\title{
Evaluation of the effects on atherosclerosis and antioxidant and antimicrobial activities of Agaricus xanthodermus poisonous mushroom
}

\author{
Betül Özaltun, Mustafa Sevindik $\odot$ \\ ${ }^{1}$ Department of Cardiology, Niğde Ömer Halisdemir University of School of Medicine, Niğde, Turkey \\ ${ }^{2}$ Department of Food Processing, Osmaniye Korkut Ata University, Bahçe Vocational High School, Osmaniye, Turkey
}

\begin{abstract}
Objectives: The aim of this study was to determine the total antioxidant capacity, total oxidant capacity, oxidative stress index and antimicrobial activity of a poisonous mushroom Agaricus xanthodermus. The effects of mushrooms on atherosclerosis are due to their antioxidant effects.

Methods: Mushroom samples collected from study field were extracted with methanol (MeOH) and dichloromethane (DCM) using soxhlet apparatus. Total antioxidant status (TAS), total oxidant status (TOS) and oxidative stress index (OSI) were measured using Rel Assay trade kits. Antimicrobial activities were tested on 9 microorganisms (Staphylococcus aureus, S. aureus MRSA, Enterococcus faecalis, Escherichia coli, Pseudomonas aeruginosa, Acinetobacter baumannii, Candida albicans, C.krusei and C. glabrata) using the modified agar dilution method.

Results: In this study A. xanthodermus has shown high antioxidant and antimicrobial activities. In addition, the highest activities of $\mathrm{MeOH}$ and DCM extracts of the mushrooms were demonstrated against E. coli, $P$. aeruginosa, and $A$. baumannii.

Conclusions: In conclusion, $A$. xanthodermus is considered to be a poisonous mushroom and can be used as a pharmacological natural agent due to its high antioxidant and antimicrobial activities.

Keywords: Medicinal mushroom, poisonous mushrooms, Agaricus xanthodermus, antioxidant, antimicrobial, atherosclerosis
\end{abstract}

U: $\mathrm{p}$ to date, approximately 140,000 mushroom species have been identified, and about 2,000 of these species are considered safe for human consumption. It has also been reported that about 700 mushroom species have therapeutic properties [1]. Serious poisoning can occur because of the misidentification natural mushrooms. Some types of mushrooms contain compounds that are toxic to humans [2]. In some countries several mushroom poisoning cases are re- ported every year. For example; in 1998, 1,675 cases of mushroom poisoning were reported in France and it is estimated that only $8,000-10,000$ cases are registered in this country in this year. Most of these cases are due to the misidentification of species because of empirical and traditional knowledge [2-4]. Although the incidence of mushroom poisoning is not known in Turkey, in the United States was reported to be 5 in $100,000[5]$. 
Agaricus xanthodermus (Yellow Stainer) is a large white mushroom with a cap resembling the horse or field mushrooms. However, the young caps are often square in shape and older caps usually have a flattened top and straighter, almost vertical sides. The gills are white initially, then pink, and later turn dark purplebrown; the pink shades are deeper than those of field mushrooms. The most distinguishing feature is that the cap and stem base turn bright chrome yellow when scratched. The smell is often unpleasant, especially when cooking [6].

General symptoms of mushroom poisoning are nausea, vomiting, diarrhea, fatigue, abdominal pain and state of consciousness change. The cardiac effects of mushroom poisoning are the most common sinus tachycardia, sinus arrhythmia, ST-T change and hypotension [2]. A. xanthodermus can cause serious stomach and intestinal pains, diarrhea, vomiting, hypotension, malaise, sweating, numb and sometimes coma. Symptoms may start after 40 minutes to 4 hours after consumption. Exactly the healing process takes several days. Some people may not develop intoxications in the consumption of mushrooms, in some people poisoning after consumption several times, while in some people shows serious symptoms in the first consumption [6-8].

Mushrooms have been used as food and medicine since ancient times [9]. Mushrooms are well in consumption of food and also in medical features. They produce secondary metabolites which have many different biological effects [10]. In previous studies, it has been reported that different mushroom species have many effects such as antioxidant, anti-lipidemic, antihypertensive, DNA preservative, analgesic, antimicrobial, anticancer, immunosuppressive, anti-allergic, anti-inflammatory and antagonistic activity [11-17]. There are lots of study about edible and toxic mushrooms and their anti-oxidative and anti-lipidemic effects. In fact, we can evaluate the anti-lipidemic and anti-oxidative effects of mushrooms as a group effect. Cardiovascular diseases are one of the most common causes of morbidity and mortality in the world [18]. There are lots of risk factors in cardiovascular disease such as hyperlipidemia, hypertension, cigarette smoking, obesity, diabetes mellitus and a positive family history of cardiovascular disease [19]. Some risk factors can be changed by lifestyle change. We can elim- inate most risk factors with a change in diet. Several food ingredients reduce hyperlipidemia, hypertension. On the other hand, the presence of antioxidant $[20,21]$ and anti-inflammatory $[22,23]$ compounds in mushrooms might be clinically relevant in the management of heart and circulation health complications. Food constituents with anti-oxidative and anti-inflammatory properties. Anti-oxidative and anti-inflammatory functions and therefore lipid lowering effects correlate with anti-atherogenic effects [24]. And also the consumption of dietary antioxidants could be important in the prevention of cardiovascular diseases $[25,26]$ and there is evidence that the oxidative modification of LDL (lipids or protein components) play a crucial role in atherogenesis [27].

In this context, it is very important to determine the pharmacological potential of poisonous, edible and non-edible mushroom species. The present study aimed to determine the antimicrobial activity, total antioxidant status (TAS), total oxidant status (TOS), oxidative stress index (OSI) of Agaricus xanthodermus Genev poisonous mushroom. In addition, the effect of fungus on atherosclerosis depending on antioxidant effect was evaluated.

\section{METHODS}

\section{Laboratory Study}

A. xanthodermus specimens were collected during routine field studies conducted in Gaziantep in 20172018. Mushroom samples was dried at 40 0C. The dried mushroom samples were pulverized by mechanical milling. Powdered mushroom samples were subjected to extraction with methanol $(\mathrm{MeOH})$ and dichloromethane (DCM) at $500 \mathrm{C}$ for about 6 hours in soxleth apparatus.

\section{TAS, TOS and OSI Tests}

Total antioxidant status (TAS), total oxidant status (TOS) and oxidative stress index (OSI) of the mushrooms were determined by Rel Assay brand commercial kits (Assay Kit Rel Diagnostics, Turkey). Trolox was used as calibrator for TAS and the results were expressed as mmoL Trolox equiv./L [28]. Hydrogen peroxide was used as the calibrator for the $\mathrm{OS}$ and the results were expressed as $\mu \mathrm{moL} \mathrm{H} 2 \mathrm{O} 2$ 
equiv./L [29]. When calculating OSI (AU: Arbitrary Unit), which is expressed as the percentage of TOS levels to TAS levels, the mmoL value in the unit of TAS test is converted to $\mu \mathrm{moL}$ as in the TOS test [29]. Analyses were carried out with 5 replicates.

\section{Antimicrobial Activity Tests}

The antimicrobial activity tests of $\mathrm{MeOH}$ and DCM extracts of the mushrooms were determined by the agar dilution method recommended by the Clinical and Laboratory Standards Institute (CLSI) and the European Committee on Antimicrobial Susceptibility Testing (EUCAST). Minimal inhibitory concentrations (MIC) for each extract were determined against standard bacteria and fungal strains. Staphylococcus aureus ATCC 29213, Staphylococcus aureus MRSA ATCC 43300, Enterococcus faecalis ATCC 29212 were used as gram positive bacteria. Escherichia coli ATCC 25922, Pseudomonas aeruginosa ATCC 27853, Acinetobacterbaumannii ATCC 19606 were used as gram negative bacteria. Candidaalbicans ATCC 10231, Candidakrusei ATCC 34135 ATCC 13803, Candidaglabrata ATCC 90030 were also used as fungi. Bacterial strains were cultured on Mueller Hinton Broth and fungal strains were cultured on RPMI 1640 Broth. To obtain a standard inoculum, the blur of bacteria and fungi was prepared according to McFarland 0.5. All extracts were tested at concentrations of 800, 400, 200, 100, 50, 25 and 12.5 $\mu \mathrm{g} / \mathrm{mL}$ and all dilutions were made with distilled water. The solvents used for the extracts were also tested for antimicrobial activity. For fungi Fluconazole, Amphotericin B was used as the reference drug, whereas for bacteria Amikacin, Ampicillin and Ciprofloxacin were used as reference drug. The lowest dilution that inhibits the growth of bacteria and fungi was determined as the minimal inhibitor concentration (MIC) [30-34].

\section{RESULTS}

\section{TAS, TOS and OSI Results}

According to our studies on A. xanthodermus 6 different mushroom samples were taken and these samples were run in 5 replicates. The results are shown in Table 1.

When our studies, it is seen that the endogenous antioxidant compound capacity that the mushroom produces is $4.229 \pm 0.153 \mathrm{mmol} / \mathrm{L}$. The oxidant compound level of the mushroom, which was produced as a result of environmental effects and metabolic activities, was determined as $29.065 \pm 0.286$ $\mu \mathrm{mol} / \mathrm{L}$. It is determined that the oxidative stress level indicating how much the oxidant compounds were tolerated with the endogenous antioxidant compounds in percentage were $0.688 \pm 0.021$.

\section{Antimicrobial Activity Results}

In this study $\mathrm{MeOH}$ and DCM extracts of $A$. xanthodermus were used and their activities on test microorganisms were determined. The results of the study were given in the Table 2 .

When Table 2 was examined, it was seen that the highest activity was determined as $\mathrm{MeOH}$ extract of the mushroom. In this study, the highest activity on $P$. aeruginosa and $A$. baumannii were seen with $\mathrm{MeOH}$ extracts in the concentration of $50 \mu \mathrm{g} / \mathrm{mL}$. The activity on $E$. coli was seen with $\mathrm{MeOH}$ and DCM extracts in the concentration of $100 \mu \mathrm{g} / \mathrm{mL}$. The activity on $C$. albicans, $C$. glabrata and C. krusei were seen with $\mathrm{MeOH}$ and DCM extracts in the concentration of 200 $\mu \mathrm{g} / \mathrm{mL}$. The highest activity on $S$. aureus MRSA was seen with $\mathrm{MeOH}$ extracts in the concentration of 200 $\mu \mathrm{g} / \mathrm{mL}$. The activity on $S$. aureus and E. faecalis were seen with $\mathrm{MeOH}$ and DCM extracts in the concentration of $400 \mu \mathrm{g} / \mathrm{mL}$.In addition, the highest activities of $\mathrm{MeOH}$ and DCM extracts of the mushrooms were demonstrated against E. coli, $P$. aeruginosa, and A. baumannii.

Table 1. TAS, TOS and OSI values

\begin{tabular}{|c|c|c|c|}
\hline & $\begin{array}{c}\text { TAS } \\
(\mathrm{mmol} / \mathrm{L})\end{array}$ & $\begin{array}{c}\text { TOS } \\
(\mu \mathrm{mol} / \mathrm{L})\end{array}$ & OSI \\
\hline A. xanthodermus & $4.229 \pm 0.153$ & $29.065 \pm 0.286$ & $0.688 \pm 0.021$ \\
\hline
\end{tabular}


Table 2. Antibacterial and antifungal activity of $A$. xanthodermus

\begin{tabular}{lccccccccc}
\hline & A & B & C & D & E & F & G & H & I \\
\hline DCM & 400 & 400 & 400 & 100 & 100 & 50 & 200 & 200 & 200 \\
MeOH & 400 & 200 & 400 & 100 & 50 & 50 & 200 & 200 & 200 \\
Ampicillin & 1.56 & 3.12 & 1.56 & 3.12 & 3.12 & - & - & - & - \\
Amikacin & - & - & - & 1.56 & 3.12 & 3.12 & - & - & - \\
Ciprofloksasin & 1.56 & 3.12 & 1.56 & 1.56 & 3.12 & 3.12 & - & - & - \\
Flukanazol & - & - & - & - & - & - & 3.12 & 3.12 & - \\
Amfoterisin B & - & - & - & - & - & - & 3.12 & 3.12 & 3.12 \\
\hline
\end{tabular}

The MIC values are presented in units of $\mu \mathrm{g} / \mathrm{mL} . \mathrm{DCM}=$ dichloromethane, $\mathrm{MeOH}=$ methanol, $\mathrm{A}=S$. aureus, $\mathrm{B}=$ S. aureus $\mathrm{MRSA}, \mathrm{C}=$ E. faecalis, $\mathrm{D}=E$. coli, $\mathrm{E}=P$. aeruginosa, $\mathrm{F}=A$. baumannii, $\mathrm{G}=C$. albicans, $\mathrm{H}=C$. glabrata, $\mathrm{I}=$ C. krusei

\section{DISCUSSION}

Most fungi-derived pharmaceuticals have been sourced from Ascomyceteous fungi where most (but not all) species produce microscopic fruiting bodies; for example, those used in pharmaceuticals include Penicillium, Aspergillus, and so on, whereas perhaps fewer pharmaceuticals, certainly in an industrial context, have been derived from the higher phyla of fungi, the Basidiomycota [35]. In this study, TAS, TOS and OSI values of a basidiomycetes species $A$. xanthodermus were determined using Rel Assay kits.As a result of the studies, the value of TAS was calculated as $4.229 \pm 0.153 \mathrm{mmol} / \mathrm{L}$, TOS value was $29.065 \pm 0.286 \mu \mathrm{mol} / \mathrm{L}$ and OSI value was $0.688 \pm$ 0.021 . No studies were conducted to determine the TAS, TOS and OSI values of A. xanthodermus. In studies conducted on literature on different types of mushrooms in the literature, the values of edible mushroom Auricularia auricula and non-edible mushroom Trametes versicolor were found to be 1.010 and 0.820 , TOS values were 23.910 and 17.760 , OSI values were 2.367 and 2.166 [36]. Edible mushroom Cyclocybe cylindracea TAS value is 4.325 , TOS value is 21.109 and OSI value is reported as 0.488 [37]. In other studies, edible mushroom Gyrodon lividus has a TAS value of 2.077, TOS value of 13.465 and OSI of 0.651 [38]. Edible mushroom Clavariadelphus truncatus TAS value is 2.415 , TOS value is 3.367 and OSI value is reported as 0.140 [39]. Poisonous mushroom Ompholatus olearius has a TAS value of 2.836, TOS value of 8.262 and OSI of 0.291 [40].
Compared to these studies, $A$. xanthodermus used in our study is lower than C. cylindracea and O. olearius, C. truncatus, A. auricula, T. versicolor and G. lividus have higher TAS values. In value of TOS, A.xanthodermus was found to be higher than $C$. cylindracea, $A$. auricula, $T$. versicolor, O. olearius, $C$. truncatus, and $G$. lividus. In addition, $A$. xanthodermus OSI value was lower than $A$. auricula and $T$. versicolor and higher than $C$. cylindracea, O. olearius, C. truncatus, and G. lividus. The reason for these differences in TAS, TOS and OSI among mushrooms is due to differences in the capacity of the product oxidant compounds, the capacity of endogenous antioxidant compounds and their ability to tolerate oxidant compounds with endogenous antioxidants with environmental and metabolic factors. As a result, it is thought that $A$. xanthodermus has high antioxidant potential and it can be used as a natural antioxidant agent by detecting the compounds that cause this effect. In addition, the protective effect of atherosclerosis can be utilized due to its antioxidant effects. We all know atherosclerosis risk factors are associated with excess ROS generation and oxidation of LDL. Ox-LDL acting on cell types promotes atherogenesis. Many pharmacologic agents that are currently in use modulate oxidative stress and improve atherogenesis [41]. In some studies traditional antioxidant supplements mostly failed in improving $\mathrm{CV}$ event rate some not. There are many factors affecting the cause of these results. One is anti-oxidant therapy was started late or exogenous antioxidants have any effects on this pathway. 


\section{Antimicrobial Activity}

Today, there are many harmful microorganisms that cause diseases. Unconscious and excessive use of antibiotics in different areas caused these microorganisms to provide resistance to antibiotics. According to clinical epidemiology analysis reports, Staphylococcus aureus, Pseudomonas aeruginosa and Acinetobacter baumannii became the most common hospital infection and drug resistant strains with infection rates of up to $50 \%$ [42]. Therefore, detection of new antimicrobial agents has become inevitable. Mushrooms are immensely rich in bioactive compounds yet largely untapped resource of useful natural compounds. These bioactive compounds are found in various cellular components and secondary metabolites, which have been isolated and identified from the fruiting bodies [43]. Mushrooms have many biological activities thanks to these bioactive compounds [39]. In the present study, $A$. xanthodermus extracts were tested on 9 different bacteria and fungus strains with antimicrobial activity. As a result of the study, $\mathrm{MeOH}$ extracts of mushrooms showed higher activity than DCM extracts. In addition, mushroom extracts were found to be more effective against gram-negative bacteria E. coli, $P$. aeruginosa and $A$. baumannii. It was previously reported that antimicrobial activity on $A$. xanthodermus was effective at different concentrations against $S$. aureus, $E$. coli and $P$. aeruginosa using different solvents $[35,44]$. In our study, $\mathrm{MeOH}$ and DCM extracts of $A$. xanthodermus were used and it was found to be effective at $50-400 \mu \mathrm{g} / \mathrm{mL}$ concentrations against test microorganisms.

\section{CONCLUSION}

In this study, a poisonous mushroom, $A$. xanthodermus's antioxidant, oxidant and antimicrobial potentials were determined. It was detected that the mushroom has antioxidant, oxidant and antimicrobial potential. Mushroom clearly has a cholesterollowering effect or hypocholesterolemic effect by different mechanisms such as decreasing very-lowdensity lipoproteins, improving lipid metabolism, inhibiting of activity of HMG-CoA reductase, and consequently preventing the development of atherosclerosis. The antioxidant and anti- inflammatory compounds occurring on mushroom also may contribute to reduce the atherosclerosis risk. A. xanthodermus should not be consumed through diet. Because A. xanthodermus is poisonous. Consumption is extremely dangerous. In our study, antioxidant and antimicrobial activities were determined. It is thought that bioactive compounds that cause this effect can be identified and used in pharmacological designs.

\section{Conflict of interest}

The authors disclosed no conflict of interest during the preparation or publication of this manuscript.

\section{Financing}

The authors disclosed that they did not receive any grant during conduction or writing of this study.

\section{REFERENCES}

1. Lima AD, Costa Fortes R, Garbi Novaes MRC, Percário S. Poisonous mushrooms; a review of the most common intoxications. Nutr Hosp 2012;27:402-8.

2. Jo WS, Hossain MA, Park SC. Toxicological profiles of poisonous, edible, and medicinal mushrooms. Mycobiology 2014;42:215-20.

3. White J, Warrel D, Eddleston M, Currie BJ, White IM, Isbister GK. Clinical toxinology --Where are we now? J Toxicol Clin Toxicol 2003;41:263-76.

4. Flesch F, Saviuc P. [Mushroom poisoning: syndromes and treatment] EMC-Médecine 2004;1:70-9. [Article in French]

5. Ecevit Ç, Hızarcıoğlu M, Gerçek PA, Gerçek H, Kayserili E, Gülez P, et al. [Evaluation of musroom intoxications presenting at the emercency department of Dr. Behçet Uz children's hospital]. ADÜ Tip Fak Derg 2004;5(3):11-14. [Article in Turkish]

6. Catcheside P, Yellow Stainer, State Herbarium Factsheet, Government of South Australia, 2017.

7. Hender E, May T, Beulke S. Poisoning due to eating fungi in Victoria. Aust Fam Physician 2000;29:1000-4.

8. Beug W, Shaw M, Cochran KW. Thirty plus years of mushroom poisoning: summary of the approximately 2,000 reports in the NAMA case registry. McIlvainea 2006;16:47-68.

9. Valverde ME, Hernández-Pérez T, Paredes-López O. Edible mushrooms: improving human health and promoting quality life. Int J Microbiol 2015; 2015:376387.

10. Calvo AM, Wilson RA, Bok JW, Keller NP. Relationship between secondary metabolism and fungal development. Microbiol Mol Biol Rev 2002;66:447-59.

11. Wieczorek Z, Siemion IZ, Bolewska-Pedyczak E, Wieland T. Immunosuppressive activity in the series of cycloamanide peptides from mushrooms. Peptides 1993;14:1-5. 
12. Badalyan SM, Innocenti G, Garibyan NG. Antagonistic activity of xylotrophic mushrooms against pathogenic fungi of cereals in dual culture. Phytopathol Mediterr 2002;41;220-5. 13. Lull C, Wichers HJ, Savelkoul HF. Antiinflammatory and immunomodulating properties of fungal metabolites. Mediators Inflamm 2005;2:63-80.

14. Ede SO, Olaniru E, Otimenyin S, Aguiyi JC, Ekwere EO. Analgesic and anti inflammatory activities of the ethanolic extract of the mushroom Ganoderma applanatum. IJRRAS 2012;13:349-52.

15. Moharib SA, El Maksoud NA, Ragab HM. Anticancer activities of mushroom polysaccharides on chemically-induced colorectal cancer in rats. J Appl Pharma Sci 2014;4:54-63.

16. Merdivan S, Lindequist U. Medicinal mushrooms with antiallergic activities. In: Agrawal DC, Tsay HS, Shyur LF, Wu YC, Wang SY, eds. Medicinal Plants and Fungi: Recent Advances in Research and Development. Springer: Singapore. 2017: pp. 93-110.

17. Yılmaz A, Yıldız S, Kılıç C, Can Z. Total phenolics, flavonoids, tannin contents and antioxidant properties of Pleurotus ostreatus cultivated on different wastes and sawdust. Int J Sec Metabolite 2017;4:1-9.

18. WHO. WHO technical report series. Diet, Nutrition and the Prevention of Chronic Disease. 2003.

19. Assmann G, Cullen P, Schulte H. Simple scoring scheme for calculating the risk of acute coronary events based on the 10-year follow-up of the prospective cardiovascular Munster (PROCAM) study. Circulation 2002;105:310-15.

20. Cheung LM, Cheung PC, Ooi VE. Antioxidant activity and total phenolics of edible mushroom extracts. Food Chem 2003;81:249-55.

21. Wong JY, Chye FY. Antioxidant properties of selected tropical wild edible mushrooms. J Food Compost Anal 2009:22:269-77. 22. Jose N, Ajith TA, Janardhanan KK. Methanol extract of the oyster mushroom, Pleurotus florida, inhibits inflammation and platelet aggregation. Phytother Res 2004;18:43-6.

23. Kohno K, Miyake M, Sano O, Tanaka-Kataoka M, Yamamoto S, Koya-Miyata S, et al. Anti-inflammatory and immunomodulatory properties of 2-amino-3H-phenoxazin-3-one. Biol Pharma Bull 2008;31:1938-45.

24. Visioli F, Poli A, Richard D, Paoletti R. Modulation of inflammation by nutritional interventions. Curr Atheroscler Rep 2008; 10:451-3.

25. García-Lafuente A, Guillamón E, Villares A, Rostagno MA, Martínez JA. Flavonoids as anti-inflammatory agents: implications in cancer and cardiovascular disease. Inflamm Res 2009;58:537-52.

26. Balsano C, Alisi A. Antioxidant effects of natural bioactive compounds. Curr Pharma Des 2009;15:3063-73.

27. Witztum JL, Steinberg D. The oxidative modification hypothesis of atherosclerosis: does it hold for humans? Trends Cardiovasc Med 2001;11:93-102.

28. Erel O. A novel automated direct measurement method for total antioxidant capacity using a new generation, more stable ABTS radical cation. Clin Biochem 2004;37:277-85.
29. Erel O. A new automated colorimetric method for measuring total oxidant status. Clin Biochem 2005;38:1103-11.

30. Bauer AW, Kirby WM, Sherris, JC, Turck M. Antibiotic susceptibility testing by a standardized single disk method. Am J Clin Pathol 1966;45:493-6.

31. Hindler J, Hochstein L, Howell A. Preparation of routine media and reagents used in antimicrobial susceptibility testing. Part 1. McFarland standards, p. 5.19.1-5.19.6. In: Isenberg HD, ed., Clinical microbiology procedures handbook, vol. 1. American Society for Microbiology, Washington, D.C. 1992.

32. EUCAST (European Committee on Antimicrobial Susceptibility Testing). Breakpoint tables Fungal isolate for interpretation of MICs. Version 7.0, 2014.

33. Matuschek E, Brown DF, Kahlmeter G. Development of the EUCAST disk diffusion antimicrobial susceptibility testing method and its implementation in routine microbiology laboratories. Clin Microbiol Infect 2014;20:255-66.

34. EUCAST (European Committee on Antimicrobial Susceptibility Testing). Breakpoint tables for Bacteria interpretation of MICs and zone diameters, Version 5.0, 2015.

35. Bala N, Aitken EA, Fechner N, Cusack A, Steadman KJ. Evaluation of antibacterial activity of Australian basidiomycetous macrofungi using a high-throughput 96-well plate assay. Pharma Biol 2011;49:492-500.

36. Akgul H, Sevindik M, Coban C, Alli H, Selamoglu Z. New approaches in traditional and complementary alternative medicine practices: Auricularia auricula and Trametes versicolor. J Tradit Med Clin Natur 2017;6:239.

37. Sevindik M, Akgul H, Bal C, Selamoglu Z. Phenolic contents, oxidant/antioxidant potential and heavy metal levels in Cyclocybe cylindracea. Indian J Pharma Edu Res 2018;52:437-41.

38. Bal C. A study on antioxidant properties of Gyrodon lividus. Eurasia J Forest Sci 2018;6:40-3.

39. Sevindik M. Investigation of oxidant and antioxidant status of edible mushroom Clavariadelphus truncatus. Mantar Dergisi 2018;9:165-8.

40. Sevindik M, Akgül H, Bal C. Determination of oxidative stress status of Ompholatus olearius gathered from Adana and Antalya Provinces in Turkey. Sakarya University Journal of Science 2017;21:324-7.

41. Li H, Horke S, Förstermann U. Oxidative stress in vascular disease and its pharmacological prevention. Trends Pharmacol Sci 2013;34:313-9.

42. Su PW, Yang CH, Yang JF, Su PY, Chuang LY. Antibacterial activities and antibacterial mechanism of Polygonum cuspidatum extracts against nosocomial drug-resistant pathogens. Molecules 2015;20:11119-30.

43. Gebreyohannes G, Nyerere A, Bii C, Berhe Sbhatu D. Determination of antimicrobial activity of extracts of indigenous wild mushrooms against pathogenic organisms. Evid Based Complement Alternat Med 2019;2019:6212673.

44. Mariselvi M, Ninganna E. Molecular identification and screening of mushrooms for antibacterial property against Pseudomonas aeruginosa and Staphylococcus aureus. J App Nat Sci 2018;10:791-6. 